ISSN: $1130-3743$

\title{
EL ESPACIO EUROPEO DE EDUCACIÓN SUPERIOR: DOCUMENTOS PARA UNA (O VARIAS) TEORÍAS DE LA EDUCACIÓN
}

\section{The European Higher Education Area: documents for one (or several) theories of education}

\section{L'Espace Européen de l'Enseignement Supérieure: documents pour une (ou plusieurs) théories de l'éducation}

Florentino SANZ FERNÁNDEZ

Universidad Nacional de Educación a Distancia. Facultad de Educación.

Departamento de Historia de la Educación y Educación Comparada. C/ Senda del Rey, 7. 28040 Madrid. Correo-e:fsanz@edu.uned.es

Fecha de recepción: enero de 2005

Fecha de aceptación definitiva: abril de 2005

BIBLID [(1130-3743) 17, 2005, 255-285]

RESUMEN

La abundancia de documentos sobre el Espacio Europeo de Educación Superior (EEES) puede conducirnos paradójicamente, si no estamos atentos, a un no-espacio, donde los documentos e informes disponibles pueden ser considerados como indicadores de conductas a poner en práctica colectivamente, en lugar de convertirse en elementos de reflexión dialógica que conduzca a la elaboración de teoría pedagógica.

El presente artículo, después de hacer una invitación a descubrir el trasfondo teórico que subyace en los distintos documentos, hace una presentación de los numerosos documentos existentes sobre el EEES. Para su mayor comprensión los sitúa en el marco amplio de los distintos organismos internacionales interesados en las 
reformas de la enseñanza superior: organismos internacionales, intergubernamentales y gubernamentales, para terminar con los documentos de mayor interés que, sobre la educación superior, se han producido en España.

Palabras clave: teorías educativas, educación superior, educación internacional, tendencias en educación, economía y educación.

\section{SUMMARY}

Paradoxically, the abundance of documents on the European Higher Education Area (EHEA) could lead us, unless we are careful, to a non-area, in which the available documents and reports are regarded as merely indicative of the processes to be collectively implemented, instead of becoming elements in a thoughtful dialogue conducive to the development of pedagogic theory.

This article, after encouraging reflection on the theoretical principles underlying the various documents, presents the numerous documents on the EHEA which are available. To make them more fully comprehensible they are situated in the wider framework of the various international bodies involved in the reforms of higher education: international bodies, intergovernmental and governmental, concluding with the most interesting documents on higher education which have been produced in Spain.

Key words: theories of education, higher education, international education, trends in education, economy and education.

\section{SOMMAIRE}

L'abondance de documents sur l'Espace Européen de l'Enseignement Supérieur (EEES) peut nous conduire, paradoxalement et si nous ne sommes pas attentifs, à non-espace, où les documents et les rapports disponibles peuvent être considérés comme autant d'indicateurs de conduites collective à mettre en pratique, au lieu de se transformer en éléments de réflexion "dialogique" conduisant à l'élaboration de théories pédagogiques.

Dans cet article, après l'exhortation à découvrir le fond théorique qui est sousjacent aux différents documents travaillés, nous effectuons une présentation des nombreux documents existants dans l'EEES. Pour une meilleure compréhension, ils sont replacés dans le cadre, au sens large, des différents organismes internationaux intéressés dans les réformes de l'enseignement supérieur: organismes internationaux, intergouvernementaux et gouvernementaux. Cet article s'intéresse également aux documents produits en Espagne présentant un intérêt direct pour l'enseignement supérieur.

Mots clef: théories éducatives, enseignement supérieure, enseignement internationale, tendances en éducation, économie et éducation. 


\section{DOCUMENTOS PARA PENSAR}

La enseñanza superior está siendo profundamente transformada en todas las regiones el mundo. Los impulsores de este cambio no son solamente las instituciones de enseñanza superior, tanto públicas como privadas, sino sobre todo organismos internacionales como el Banco Mundial (BM), la Organización Mundial del Comercio (OMC) o la UNESCO; distintas organizaciones intergubernamentales como la Organización para la Cooperación y el Desarrollo Económicos (OCDE), la Unión Europea (UE) o la Organización de Estados Iberoamericanos (OEI) y los diferentes Estados que se suman a la corriente de este gran movimiento.

La abundante producción de informes y estudios en este campo no puede ser dejada de lado por los implicados directamente en la universidad (profesores, alumnos y gestores de centros de enseñanza superior) que quieran conocer en profundidad los cambios que se demandan y participar activamente en ellos. Particularmente, los pedagogos no deben permanecer ajenos al análisis del paradigma o paradigmas educativos que subyacen en este movimiento de reforma.

A partir de las exigencias que el Espacio Europeo de Educación Superior (EEES) está planteando a todas las universidades de la Unión Europea, es urgente hacer un análisis detallado de la normativa y documentación existentes que nos permita no solamente construir la historia de este proceso sino también descubrir el proyecto o los proyectos teóricos que la Unión Europea tiene sobre la enseñanza superior. Porque efectivamente, ante tanta documentación, se pueden adoptar varias posturas: la del curioso que quiere enterarse de lo que hay y de lo que dicen para estar, profesionalmente, bien informado; la del eficiente que ha de estar enterado para poner en práctica la reforma; y la del reflexivo que quiere tener los elementos necesarios para, con ellos, descubrir la o las teorías que subyacen y, además, participar, desde ellos, en la construcción teórica de la realidad pedagógica europea.

La presentación que hacemos en este artículo de los diferentes documentos no tiene sólo, por objetivo, satisfacer al curioso y facilitar al eficiente la puesta en práctica de la reforma propuesta, sino provocar a la reflexión e invitar a la construcción teórica. La información, ya se sabe, es la primera etapa, imprescindible pero insuficiente, de todo un proceso que conduce, si se continúa, a la ciencia y, después, a la sabiduría. Modestamente, no queremos pararnos en la primera etapa informativa, pero reconocemos que, sin información, difícilmente se puede construir ciencia.

Un primer riesgo que corremos al enfrentarnos a tanta información es la de convertir el espacio europeo en un espacio no-lugar. La gran cantidad de documentos, con los que nos estamos encontrando, nos está conduciendo al terreno solitario de lo que algunos autores (Marc Augé, 1992) denominan no-lugar. Según este autor existen tres figuras del exceso que caracterizan la sobremodernidad: la superabundancia de acontecimientos, la superabundancia de espacio y la individualización de las referencias que derivan en los espacios no-lugares. El espacio no-lugar es un espacio característico de la sobremodernidad en el que, dada la 
superabundancia de elementos, para convivir, no se necesita conversar con nadie sino seguir los indicadores formales que señalan la dirección. Algo así como lo que nos ocurre en los supermercados cuando caminamos guiados por las etiquetas de los precios sin necesidad de hablar ni siquiera con la cajera; cuando nos movemos por los aeropuertos, en solitario, siguiendo las indicaciones colectivas de los paneles o como cuando circulamos por las autopistas evitando las poblaciones de los lugareños por las que pasamos al lado. La multiplicidad y la super-presencia de los otros exige la disciplina de no "entre-tenerse" sino de ir "a lo que hay que ir", como si el fin a donde vamos nos viniera dado de forma indiscutible y no tuviéramos más remedio que aceptarlo como una herencia pasiva. Las flechas y las etiquetas sustituyen a la conversación y al diálogo en las nuevas plazas públicas a donde se acude para no participar ni hablar con nadie. Aplicado a nuestro caso, la superabundancia de documentos sobre el EEES puede conducirnos paradójicamente, si no estamos atentos, a un no-espacio, donde los documentos e informes disponibles pueden ser considerados como indicadores de conductas a poner en práctica colectivamente, en lugar de convertirse en elementos de reflexión dialógica.

Debajo de todos los documentos e informes sobre la enseñanza superior en el mundo, y en concreto sobre el EEES, existen diferentes relatos que cualquier pedagogo profesional no debe obviar si se quiere considerar protagonista de la construcción teórica. Pero ¿cuál es este relato o cuáles son estos relatos? ¿Cuáles son las razones últimas que están justificando y legitimando los cambios propuestos? ¿Qué proyecto teórico educativo subyace a tanta documentación?

Este trabajo no pretende responder a estas preguntas pero sí quiere plantearlas como un primer eslabón de reflexión teórica y, además, quiere facilitar su respuesta aportando ordenadamente una serie de elementos necesarios para obtenerla.

En primer lugar parece legítimo plantear la pregunta sobre cuál es el relato de fondo del EEES y cuál es la razón de ser de las reformas que se plantean y, al mismo tiempo, es también obvio para cualquier científico dialógico, no considerar que las respuestas están ya dadas por los autores de los documentos que aquí se presentan.

Por muy grande que sea la fuerza de estos intelectuales orgánicos, los teóricos de la educación tendrán que entrar en diálogo con ellos a través de sus textos y utilizando probablemente otras claves diferentes a las "políticamente correctas". No se trata, por principio, de salirse irresponsablemente de las coordenadas de convivencia social en las que estamos, pero sí de construir la verdad desde la libertad y la autonomía, propias del científico. En este sentido habría que afirmar que no es sólo la verdad la que hace libres sino que también es la libertad la que hace verdaderos.

La libertad del pedagogo, ante la dinámica generada en las reformas de la educación superior, le exigiría entre otras cosas y en este caso, escudriñar, por ejemplo, el modelo de desarrollo que promociona el Banco Mundial en los documentos que este organismo elabora sobre el aprendizaje y la formación, el concepto de comercio del que se sirve la Organización Mundial del Comercio para liberalizar los servicios educativos, las diferencias entre el discurso social que emplea la 
UNESCO y los discursos elitistas de la OMC. En cuanto a Europa, ya han manifestado algunos pedagogos (Gómez del Castillo, 2004; Jiménez Aguilera, 2004) el temor fundado de que el objetivo último de las nuevas políticas educativas alentadas sea convertirla en una potencia económica, capaz de enfrentarse a Estados Unidos y Japón en la batalla por el dominio del mundo, sin poner el necesario cuidado en el desarrollo del ser humano en cuanto individuo y como miembro de una sociedad constituida por el conjunto de la humanidad.

Además de aprender a intuir los diferentes marcos teóricos en los que están encajados los elementos conceptuales que acabamos de enumerar, es legítimo preguntarse también sobre las consecuencias sociales a las que el modelo de reforma del EEES conduce: ¿Lo que se quiere es tener ciudadanos o productores? ¿Va a conducir a tener gente competente o competitiva? ¿Forma ciudadanos para que participen en torno a procesos ya en marcha o a que gestionen proyectos? ¿Va a generar una sociedad dual o una sociedad integradora? Y por qué no preguntarse por la jerarquía de valores que incluye este modelo: ¿El objetivo último es el poder hacer de Europa una potencia que pueda plantar cara a Norteamérica y Japón? Son preguntas de gran calado que no aparecen expuestas con claridad en la narración de los documentos sino en el discurso complejo y, a veces, disperso, de la multiplicidad de los documentos.

Sin embargo, la libertad del científico no es tan simple como elegir lo uno o lo otro. El álgebra lógica, desarrollada a principios del siglo XIX por el matemático George Boole para investigar las leyes fundamentales en que se basa el razonamiento humano, tiene como característica especial que sus variables sólo pueden adoptar dos valores, tradicionalmente denominados cierto o falso y que usualmente se representan con 1 y 0 respectivamente. Esta dinámica de lógica binaria acostumbra a construir verdades desde el sí o el no, del blanco o negro, del nosotros o los otros, dentro o fuera, bueno o malo, arriba o abajo, verdadero o falso, masculino o femenino, cristiano o pagano, libre o seguro, autónomo o dependiente, creativo o determinado, sano o enfermo, integrado o excluido, y pretende impulsar una forma simple de investigar que supone estar o de un lado o del otro sin posibilidad alguna de construir teorías complejas, compuestas de pertenencias plurales que interactúan entre sí.

La lógica binaria simplifica la vida para no encontrarse ni con la agonía ni con la tragedia, propias de las democracias avanzadas y de los modelos dialógicos de investigación. Agonía, que no tiene nada que ver con la muerte sino con la lucha por vivir y tragedia, que no tiene nada que ver con el dolor sino con la superación de dos alternativas, a parentemente contradictorias, que pueden ser igualmente válidas. La lógica binaria va por el camino más rápido al encuentro de verdades que, al mínimo soplo, se derrumban porque están apoyadas en simplificaciones formales ya atrasadas. Como diría Edgard Morin (2001), es imposible comprender el mundo tan complejo en el que estamos si seguimos utilizando un instrumental tan simple. Efectivamente, se necesita un instrumental complejo para trabajar los diferentes relatos implícitos en la multitud de documentos presentados en este artículo. 
Lo que este artículo considera es la necesidad de plantear la pregunta sobre el paradigma educativo que subyace al EEES y facilitar el esfuerzo de localizar y clasificar los documentos en el que este paradigma está contextualizado. No se considera que la respuesta a la gran pregunta sobre qué el EEES esté solo en tener la información. La forma de clasificar la información, la inclusión entre los documentos oficiales de documentos críticos, que es lo que se hace en este artículo, es ya, a nuestro juicio, una manera de iniciar la reflexión pero es sólo eso, un inicio. La manera de informar forma parte de un proceso de teorización pedagógica sobre el EEES pero, al considerar la información como insuficiente, esperamos que esta aportación contribuya a facilitar el debate teórico. Éste es nuestro propósito.

\section{INFORMES DE LOS ORGANISMOS INTERNACIONALES SOBRE LA ENSEÑANZA SUPERIOR}

Seleccionamos algunos de los organismos internacionales más relacionados, desde una perspectiva u otra, con la enseñaza superior y que hayan elaborado algún documento o desarrollado alguna dinámica que incida en ella.

\subsection{La UNESCO}

En 1995, para aplicar una resolución de la 27 Conferencia General, se inicia una agenda sobre educación superior con un borrador de estudio sobre El cambio $y$ desarrollo de la Enseñanza Superior ${ }^{1}$ que, después de una serie de conferencias regionales en La Habana, noviembre de 1996, Dakar, abril de 1997, Tokyo, julio de 1997, Palermo, septiembre de 1997 y Beyrouth, marzo de 1998, da lugar a la Conferencia Mundial de Educación Superior (CMES, 1998) sobre el tema la Enseñanza superior en el siglo XXI: visiones y acciones ${ }^{2}$. A los cinco años siguientes tiene lugar la última conferencia del 2003 que concluye con un informe sobre Las tendencias y los desarrollos de la Enseñanza superior en Europa ${ }^{3}$.

Esta iniciativa sobre la enseñanza superior que lleva a cabo la UNESCO no es una iniciativa aislada sino que está situada en un programa más amplio que tiene por fin repensar todo el sistema educativo ante los nuevos contextos y del que forman parte, entre otros, los siguientes acontecimientos: la Conferencia de Jomtien (Tailandia), en 1990, sobre la educación básica; la 45 Conferencia Internacional de Ginebra, en 1996, para reforzar el papel de los profesores en un mundo en mutación; el II Congreso Internacional de Educación e Informática: políticas educativas y nuevas tecnologías, apadrinado por la UNESCO y celebrado en Moscú en 1996; la Quinta Conferencia Internacional sobre la educación de personas adultas celebrada

1. http://www.unesco.org/education/pdf/24_235_f.pdf.

2. http://www.crue.org/dfunesco.htm y http://www.rau.edu.uy/docs/paris1.htm\#declaracion.

3. http://portal.unesco.org/education/fr/file_download.php/75cc7602f686acfc78ce583e $986 \mathrm{de} 66$ dEurope_rapF.pdf. 
en Hamburgo, en el año 1997; la Conferencia intergubernamental sobre políticas culturales y desarrollo de Estocolmo de 1998; el II Congreso Internacional sobre la enseñanza técnica y profesional-Educación y formación a lo largo de la vida: un puente hacia el futuro (Seúl, 1999)- y la Conferencia Mundial sobre la ciencia para el siglo XXI: un nuevo compromiso (Budapest, 1999). Es en este contexto amplio en el que se repiensa lo que ha de ser la educación, la ciencia y la cultura y en el que tiene lugar, en 1998, la Conferencia Mundial sobre Educación Superior con el objetivo de establecer unos principios de reforma profunda en este subsistema.

Los temas de debate de la Conferencia de París de 1998 sobre enseñanza superior intentaron responder a los sugeridos en las conferencias regionales previas que fueron los siguientes: responder a las exigencias del mundo del trabajo ${ }^{4}$, enseñanza superior y desarrollo humano sostenible ${ }^{5}$, contribución al desarrollo nacional y regional $^{6}$, el personal en la enseñanza superior ${ }^{7}$, la ènseñanza superior en una nueva sociedad desde el punto de vista del estudiante ${ }^{8}$, desde lo tradicional a lo virtual o las nuevas tecnologías de la información ${ }^{9}$, desafíos y oportunidades de la enseñanza superior y la investigación ${ }^{10}$, la contribución de la enseñanza superior

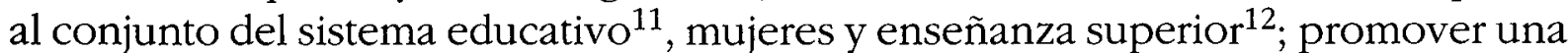
cultura de la paz ${ }^{13}$, movilizar el poder de la $\mathrm{paz}^{14}$ y autonomía, responsabilidad social y libertad académica ${ }^{15}$.

En junio del 2003 tuvo lugar en París la Conferencia Mundial sobre la Educación Superior +5 , que se celebró en la sede de la UNESCO para evaluar los cambios

4. http://portal.unesco.org/education/fr/file_download.php/6214fa21ba71b2727f534c829df768 e8travail.pdf.

5. http://portal.unesco.org/education/fr/file_download.php/3956c8d708a08ca1c2cb5b4d4 ae5c4cedev_hum_durable.pdf.

6. http://portal.unesco.org/education/fr/file_download.php/c5f8d3b6a2f08f7ce40de4aebc2e 4729dev_nat_reg.pdf.

7. http://portal.unesco.org/education/fr/file_download.php/6bcdc85843610b5e98532bb35aa 638c4personnel.pdf.

8. http://portal.unesco.org/education/fr/file_download.php/c9aa5f031bf6ea98b3a138fc938c9404 etudiants.pdf.

9. http://portal.unesco.org/education/fr/file_download.php/65cf08c296d0a6fb0e09bc8531e9849 cnouvelles_tech.pdf.

10. http://portal.unesco.org/education/fr/file_download.php/fb029a2df5882d32aea0fd7a 3179d398recherche.pdf.

11. http://portal.unesco.org/education/fr/file_download.php/20c61bbce2a653bb27608 58a69ba2e8asysteme_ed.pdf.

12. http://portal.unesco.org/education/fr/file_download.php/530e7004f9329e025abdb 9f1dcbf0e71femmes.pdf.

13. http://portal.unesco.org/education/fr/file_download.php/09892a56eab3aea5f504a87 84bb2d560culture_paix.pdf.

14. http://portal.unesco.org/education/fr/file_download.php/2a41a14257c65ba9f4162e2 44f5d8bf5pouvoir_culture.pdf.

15. http://portal.unesco.org/education/fr/file_download.php/b088645e2965c6e358aa5ed5 c2300bf7autonomie.pdf. 
producidos en la enseñanza superior a lo largo de los cinco años transcurridos desde que tuvo lugar la anterior Conferencia en París.

Una amplia información de todo este proceso puede encontrarse en http://portal.unesco.org/education y pulsando, desde ahí, el enlace de educación superior.

El discurso de la UNESCO es un discurso social e integrador de los diferentes ámbitos de la vida humana y cuyos referentes no son exclusiva ni prioritariamente los relacionados con el ámbito productivo, aunque, lógicamente, este ámbito no queda excluido. Esto no quiere decir, sin embargo, que este discurso sea el dominante, debido a que el poder de influencia de la UNESCO, al lado del de otros organismos internacionales, está más aminorado.

\subsection{El Banco Mundial}

El BM es uno de los organismos internacionales que, desde 1994, viene incidiendo con más insistencia en educación y está impulsando un modelo de enseñanza superior muy ligado al paradigma del desarrollo productivo y económico. En este sentido el discurso del BM es distinto y a veces distante del modelo de desarrollo de la UNESCO y del Programa de las Naciones Unidas para el Desarrollo (PNUD) que vienen impulsando un modelo de desarrollo más integrador de las distintas dimensiones humanas, además de la economía.

Los documentos más importantes del BM sobre la enseñanza superior hay que retrotraerlos a su conocido informe, del año 1994, sobre La educación Superior: Lecciones derivadas de la experiencia ${ }^{16}$. Es un estudio que forma parte de una investigación más general sobre las distintas modalidades de enseñanza y que se inició con dos documentos de política educativa titulados Educación Primaria (Banco Mundial, 1992) y Educación Técnica y Formación Profesional (Banco Mundial, 1992), de tal forma que el estudio sobre educación superior es el tercer informe de este bloque. Los problemas fundamentales que se identifican son: aumento de la demanda, limitaciones presupuestarias, falta de adecuación a los cambios de la sociedad, ineficiencia y baja calidad. Todos ellos muy relacionados con el ámbito de la productividad y la rentabilidad económica.

Una crítica a esta visión del Banco Mundial se puede encontrar en análisis ${ }^{17}$ como los que, por ejemplo, realizan Coraggio y Torres, 1997; Medialdea y Alonso,

16. http://www.bancomundial.org.mx/bancomundial/SitioBM.nsf/vwCatPubEsp/98D004FEF ACA8A3C06256E7E0069272A?OpenDocument\&pag $=6.2 \&$ nivel $=6$.

17. Se puede comenzar este análisis crítico al Banco Mundial por la lectura de MEDialdEA, B. y Atonso, V. Las reformas neoliberales de la educación en el mundo, consultado en noviembre del 2004 en http://www.nodo50.org/caum/educacion/contenedor/victoralonso.htm\#2.\%20Análisis. También se puede consultar el libro de CORAGGIO, J. L. y TORRES, R. M. Las propuestas del banco mundial para la educación: ¿sentido oculto o problemas de concepción? Se puede encontrar en http://www.fronesis.org/ rmtorres.htm. 
2004. Con posterioridad al 1994, el BM ha publicado otros documentos entre los que hay que destacar:

- La educación superior en los países en desarrollo: peligros y promesas ${ }^{18}$ (2000), elaborado conjuntamente por el Banco Mundial y la UNESCO y en el que, después de ampliar el análisis del documento de 1994, hace énfasis en el papel emergente del conocimiento como principal motor del desarrollo económico, la aparición de nuevos proveedores de educación superior en un contexto de educación sin fronteras, la aparición tanto de fuerzas de mercado en la educación terciaria como de un mercado global de capital humano avanzado y el incremento de solicitudes, de los países clientes del Banco Mundial, en ayuda de apoyo financiero y técnico para la reforma y el desarrollo de la educación superior.

- Construir Sociedades de Conocimiento: Nuevos Desafios para la Educación terciaria, publicado en el 2003 por el Banco Internacional de Reconstrucción y Fomento/Banco Mundial. Una educación terciaria, según este informe, contribuye a impulsar el crecimiento económico, reduce la pobreza y encara el desafío de la globalización y, al mejorar la preparación de la fuerza laboral, brinda mejores oportunidades de empleo e ingresos.

- Aprendizaje permanente en la economía global del conocimiento: desafios para los países en desarrollo. Esta obra afronta los asuntos y desafíos cruciales de la educación en una economía del conocimiento y explora las vías que utilizan los sistemas de aprendizaje permanente para fomentar el desarrollo. Los autores tratan el carácter cambiante del aprendizaje y el papel cada vez más sobresaliente del sector privado en la formación y la capacitación en todo el mundo.

Todos estos documentos se pueden encontrar haciendo el siguiente recorrido: http://www.bancomundial.org.mx y pulsando en la ventana Centros de información pública http://www.bancomundial.org.mx/bancomundial/SitioBM. nsf/Menu 6?OpenForm\&pag=6.0\&nivel=6 y pulsar en documentos en español http://www. bancomundial.org. $\mathrm{mx} /$ Bancomundial/SitioBM.nsf/Menu63?OpenForm\&pag $=6.2 \&$ nivel $=6$ y pulsar en educación http://www.bancomundial.org. $\mathrm{mx} /$ Bancomundial/ SitioBM.nsf/Menu63? OpenForm\&pag $=6.2 \&$ nivel $=6$.

El discurso del Banco Mundial hay que situarlo dentro del contexto del Consenso de Washington, conocido como el gran impulsor de una política del máximo mercado. Según esta orientación política, no es el Estado el mejor regulador de los servicios sociales sino que éstos se rentabilizan más y se distribuyen mejor a través del mercado. El Acuerdo General de Servicios de la Organización Mundial del

18. http://www.bancomundial.org.mx/bancomundial/SitioBM.nsf/vwCatPubEsp/D0E56CDA 04503E9D06256E7E0068D17F?OpenDocument\&pag=6.2\&nivel $=6$. 
Comercio dará un gran impulso también a esta forma de regular mundialmente la educación, de la que no son ajenas distintas organizaciones intergubernamentales como la Unión Europea, la Organización de Estados Iberoamericanos y la OCDE, además de los Estados más poderosos del mundo, liderados por la administración de los Estados Unidos.

\subsection{La Organización Mundial del Comercio (OMC)}

Un problema sin definir claramente en los documentos europeos es si la educación forma parte de los servicios a comercializar. En el texto del AGCS se afirma inicialmente que quedan excluidos de la liberalización aquellos servicios que son suministrados en ejercicio de facultades gubernamentales (art. 13.b). Un servicio suministrado en ejercicio de facultades gubernamentales significa todo servicio que no se suministre en condiciones comerciales (cobrando una tasa) ni en competencia con uno o varios proveedores de servicios (art. 13.c). Según esto los servicios públicos de la educación o la sanidad, para los que no existe, en el Acuerdo, ninguna mención específica, a pesar de ser derechos sociales básicos de los ciudadanos, quedarían incluidos en la mercantilización de los servicios y tan sólo quedan fuera los bancos centrales, la policía, la justicia y la defensa nacional.

El Parlamento Europeo considera formalmente que los servicios de interés general que forman parte de las funciones esenciales de las autoridades públicas, tales como la educación, la salud pública, la vivienda pública y social, junto con los servicios sociales que asumen funciones de seguridad social y de inserción social, no entran en el ámbito de aplicación de la legislación de la Unión Europea en materia de competencia, por lo que sólo deberían estar sujetos a la supervisión de la Comisión en caso de apariencia de abuso de poder discrecional en la definición de tales servicios (Resolución del Parlamento Europeo sobre el Libro Verde sobre los servicios de interés general (COM[2003] 270 - 003/2152[INI]). Pero esto es lo que piensa una de las muchas voces que componen la $\mathrm{OMC}$, puesto que la Unión Europea es considerada como un solo miembro de este organismo.

La sociedad civil mundial ha mantenido una gran preocupación sobre la liberalización de los servicios educativos y sobre el cambio de denominación de los Servicios de Interés General que vendrían a sustituir a los tradicionales Servicios Sociales. Lo que preocupa a muchos ciudadanos, ante los hechos reales que se van sucediendo cada vez más vertiginosamente en este sentido, es si los servicios educativos se van a comercializar o no. Según algunos estudios recientes existe una orientación de los estudios superiores hacia el polo del mercado. 


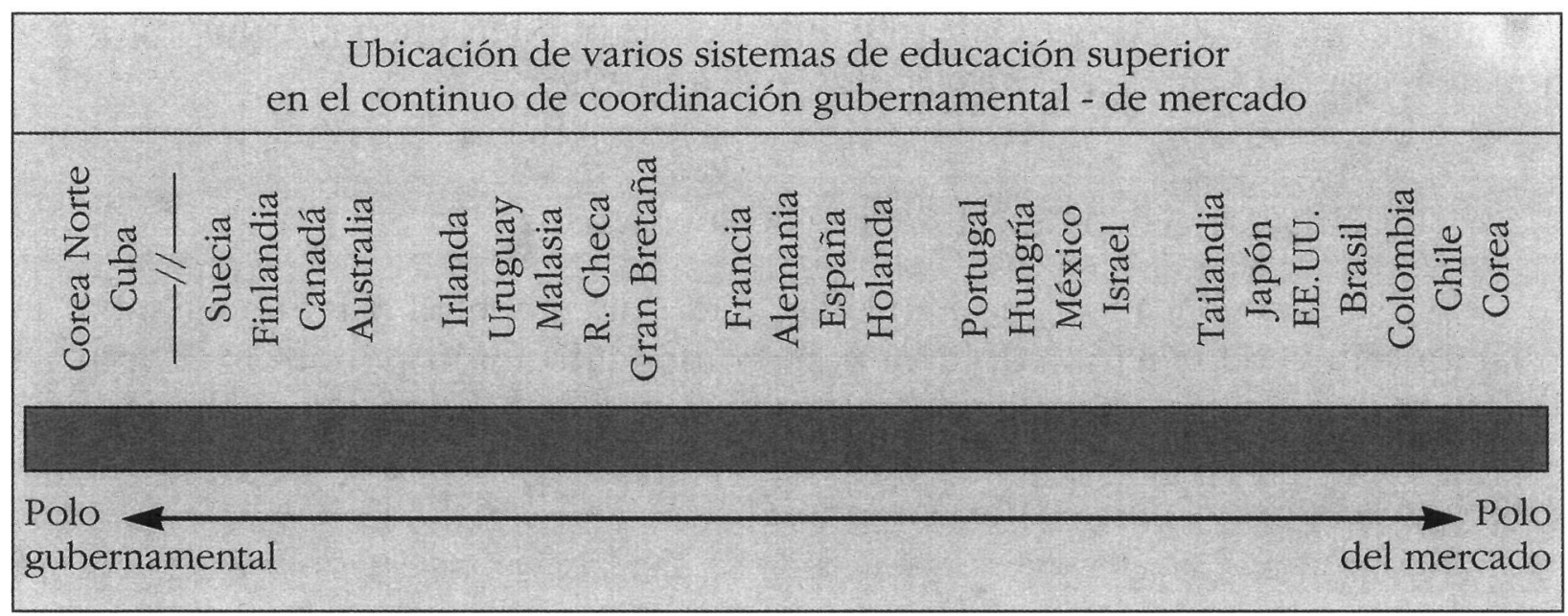

Fuente: BRUNNER (2005) Informe sobre la educación Superior en Chile. Universidad Adolfo Ibáñez.

Toda esta problemática nos conduce a la importancia que, para la enseñanza superior, está teniendo la OMC y, en concreto, el AGCS. Las fuentes de documentos sobre esta problemática provienen, como es lógico, de la misma OMC pero también de otros organismos como la Unión Europea, la UNESCO, las asociaciones universitarias y las distintas organizaciones de la sociedad civil. Veamos algunos de ellos:

\subsubsection{El Acuerdo General sobre la Comercialización de Servicios (AGCS)}

Respecto la Organización Mundial del Comercio, es importante conocer toda la evolución sobre el Acuerdo General sobre el Comercio de Servicios (AGCS) ${ }^{19}$ cuyo proceso de aplicación tiene previsto su fin en la VI Conferencia que tendrá lugar, en Hong Kong, en diciembre de 2005. Este acuerdo pretende la liberalización de múltiples categorías de servicios que afectan al medio ambiente, recursos naturales, cultura, comunicación, educación, sanidad, seguridad social, transporte, y a los servicios públicos con carácter general. Evidentemente, son parcelas fundamentales que afectan directamente a la calidad de vida de la población. La OMC pretende proveer estos servicios y ampliar su extensión mediante el poder del mercado. La justificación de la bondad de esta liberalización de servicios se puede encontrar en un documento realizado por la misma OMC titulado AGCS: Realidad y Ficción ${ }^{20}$. Otros documentos marco que se pueden considerar de interés son el Informe sobre el Comercio Mundial de $2004^{21}$ o las Estadísticas del comercio

19. http://www.jurisint.org/pub/06/sp/doc/25.htm y http://www.wto.org/spanish/docs_s/legal_ s/26-gats.pdf.

20. http://www.wto.org/spanish/tratop_s/serv_s/gatsfacts1004_s.pdf.

21. http://www.wto.org/spanish/res_s/booksp_s/anrep_s/world_trade_report04_s.pdf. 
Internacional 222004 de la OMC. En Internet se pueden encontrar los Informes anuales sobre el Comercio Mundial desde el año $1998^{23}$.

\subsubsection{La UNESCO y la comercialización de la enseñanza}

Entre los organismos que han presentado documentos o informes sobre la relación entre educación superior y su comercialización podemos citar al de la UNESCO sobre la Educación superior en una sociedad mundializada, en el que se alude directamente a las relaciones entre el Acuerdo General de Comercialización de Servicios y la enseñanza superior ${ }^{24}$.

\subsubsection{La Unión Europea y la comercialización de la enseñanza}

Hemos de decir que la Unión Europea lleva varios años reflexionando sobre los Servicios de Interés General (S.I.G). Ello desembocó en la presentación, en mayo de 2003, de un libro verde, en el que la Comisión Europea presentaba un balance de las reflexiones y de la atención prestada a los S.I.G. a escala comunitaria y nacional. Es muy útil seguir el debate producido a partir del Libro Verde sobre comercialización de Servicios de Interés General ${ }^{25}$ y sobre La Directiva del Parlamento Europeo y del Consejo relativa a los servicios en el mercado interior ${ }^{26}$, presentada por la Comisión. Un documento de interés, en el aspecto económico, es la comunicación de la Comisión de las Comunidades Europeas sobre Invertir eficazmente en educación y formación: un imperativo para Europa ${ }^{27}$ (Bruselas, 10.01.2003 COM[2002] 779 final) en donde se promueve una mayor inversión privada para la formación.

\subsubsection{Iberoamérica y la comercialización educativa}

La III Cumbre Iberoamericana de Rectores de Universidades Públicas ha publicado un documento sobre la educación superior y el Acuerdo General de Comercialización de Servicios que lleva por título Carta de Porto Alegre ${ }^{28}$.

El Foro Latinoamericano de Políticas Educativas -FLAPE- viene realizando un debate de gran interés que ha comenzado con un texto base del profesor Hugo

22. http://www.wto.org/spanish/res_s/statis_s/its2004_s/its2004_s.pdf.

23. http://www.wto.org/spanish/res_s/reser_s/annual_report_s.htm.

24. http://www.iesalc.unesco.org.ve/pruebaobservatorio/documentos $\% 20$ pdf/educaci $\%$ F3n\%20superior\%20en\%20una\%20sociedad\%20mundializada.pdf.

25. http://europa.eu.int/eur-lex/es/com/gpr/2003/com2003_0270es01.pdf

$26 \mathrm{http} / /$ www.europa.eu.int/eur-lex/es/com/pdf/2004/com2004_0002es01.pdf.

27. http://europa.eu.int/eur-lex/es/com/cnc/2002/com2002_0779es01.pdf.

28. http://www.columbus-web.com/es/partej/portoalegre.html. 
Aboites (México) sobre el tema del "Libre Comercio y Educación Superior en América Latina", y de textos especialmente elaborados por expertos de Brasil, Chile, Colombia y Perú, que se pueden consultar en la red del Foro ${ }^{29}$.

\subsubsection{Diferentes organismos ante la comercialización de la educación}

Asociaciones internacionales de educación superior como la Asociación de Universidades de Canadá30 (AUCC), el American Council on Education (ACE), l'Association Européenne de l'Université (AEU) et le Council for Higher Education Accreditation (CHEA) publicaron una Declaración conjunta sobre la enseñanza superior y el Acuerdo General sobre el Comercio de Servicios ${ }^{31}$.

Diferentes países han hecho unas declaraciones explícitas a la Organización General del Comercio sobre los servicios de enseñanza como por ejemplo Australia ${ }^{32}$, Japón ${ }^{33}$, Nueva Zelanda ${ }^{34}$ y Estados Unidos ${ }^{35}$.

Entre los estudios comparados sobre la situación de la educación superior en el mundo ante el desafío del mercado pueden citarse el de Clark (1998) o el coordinado por José Joaquín Brunner (2005). Según el triángulo de Clark, los sistemas educativos superiores, tanto de Europa Continental como de América Latina, han girado tradicionalmente en torno al eje $\mathrm{A} / \mathrm{B}$ hasta las dos últimas décadas en las que todos los sistemas de educación superior han comenzado a alejarse del eje $\mathrm{A} / \mathrm{B}$ y se han dirigido hacia el ángulo $\mathrm{C}$ que representa la tendencia del mercado. Para una mayor documentación sobre este giro pueden consultarse las dos obras citadas así como la bibliografía ofrecida por Brunner (2005) en el anexo 1.

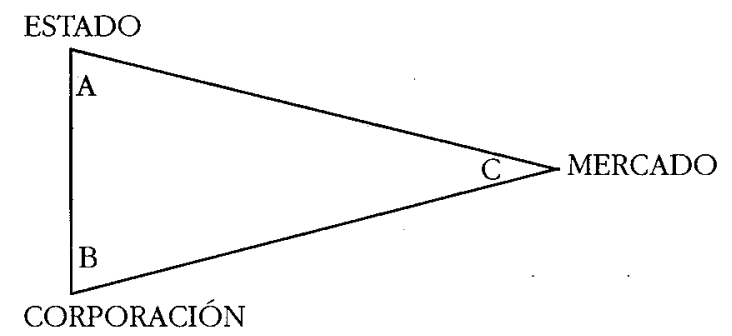

29. http://www.foro-latino.org/fv3.htm y http://www.foro-latino.org/documentos/texto-baseaboites.pdf.

30. Un estudio realizado en Canadá sobre el Acuerdo General sobre el Comercio de Servicios puede ser de gran interés para conocer cómo se está aplicando en la enseñanza superior; lleva por título L'AGCS et l'enseignement supérieur au Canadá http://www.aucc.ca/_pdf/francais/reports/2003/ gats_update_f.pdf.

31. http://www.columbus-web.com/es/partej/declaracion.doc.

32. http://www.columbus-web.com/es/partej/W110\%202.doc.

33. http://www.columbus-web.com/es/partej/W137.doc.

34. http://www.columbus-web.com/es/partej/W93.doc.

35. http://www.columbus-web.com/es/partej/W93.doc.

36. http://www.uai.cl/fset/index_temp.html?url=/p4_home/site/pags/20050121095042.html. 


\subsubsection{El pensamiento crítico sobre la comercialización de la educación}

Determinados colectivos ciudadanos han reaccionado ante este problema oponiéndose a la mercantilización de los servicios porque temen que dejen de ser un derecho para convertirse en un objeto de consumo y porque sospechan que la educación deje de ser un servicio social para convertirse en sólo un servicio de interés general. Igualmente piensan que mercantilizar la educación es convertirla en un espacio de competitividad en lugar de ser un ámbito de cooperación y que con la mercantilización educativa se produzca una aceleración de la dualidad social. Existen varias plataformas específicas de pensamiento crítico sobre la mercantilización de servicios que citamos entre otras muchas:

- La Asociación para la Tasa sobre las Transacciones Especulativas para Ayuda a los Ciudadanos (ATTAC) ha publicado un análisis sobre comercialización de servicios: Transformar Europa en una zona económica especial. La Directiva de la UE sobre Servicios ${ }^{37}$.

- El Observatorio antiliberal de la educación y de servicios públicos ${ }^{38}$ tiene un dossier relevante en este ámbito.

- Intermon OXFAM Internacional es otro foro crítico a la comercialización en donde se puede encontrar análisis alternativos sobre la comercialización. Podemos destacar dos grandes títulos, uno sobre la problemática mundial del comercio titulado Cambiar las reglas. Comercio, globalización y lucha contra la pobreza ${ }^{39}$ y otro, más centrado en la problemática europea, que lleva por título Nueva agresión neoliberal de la Comisión Europed ${ }^{40}$.

- El Foro Mundial Social y los Foros Sociales Regionales han elaborado también debates en este sentido. Se pueden ver los organizados en Zaragoza por el Foro Social de Aragón y Attac de Aragón: Movimiento Internacional por la Democratización de los Mercados Financieros y sus Instituciones ${ }^{41}$.

- El Club de Amigos de la UNESCO de Madrid (CAUM) organiza una serie de seminarios y talleres sobre educación en los que analizan críticamente el tema de la comercialización educativa. Por su interés podemos introducir un texto, entre otros, de los publicados por el CAUM (Nico Hirt, 2002) y titulado Los tres ejes de la mercantilización escolar ${ }^{42}$.

37. http://www.attacaragon.org/otros/Directiva\%20UE[1],\%20Analisis\%20ATTAC.doc.

38. http://www.oale.org/spip/article.php3?id_article=335.

39. http://www.comercioconjusticia.com/es/assets/espanol/CambiarReglasetiqueta_cover_ and_index.pdf.

40. http://www.attacaragon.org/otros/Directiva\%20UE\%20analisis\%20OXFAM.doc.

41. http://www.attacaragon.org/Textos/AGCS.htm\#AGCS1 y http://www.attacaragon.org/.

42. http://www.aep.pangea.org/nousdocs/Universitat_publica/opinio/3\%20ejes $\% 20$ de $\% 201 \mathrm{a}$ $\% 20$ mercantilizacion $\% 20$ escolar.pdf. 
- El periódico Le Monde diplomatique $e^{43}$ ha sido también otro de los foros críticos. En él se puede leer artículos como el de Gerard de Selys (1998) sobre L'école, grand marché $d u X X I^{e}$ siècle $e^{44}$ en el que aparece una reflexión de conjunto sobre la problemática de fondo que subyace en muchos de los documentos internacionales que nosotros citamos en este artículo.

- La asociación francesa Appel pour une école democratique (APPED) tiene un dossier específico, disponible en Internet, sobre la enseñanza y la economía y sobre el mercado de la enseñanza ${ }^{45}$. También publican una revista titulada L'école democratique ${ }^{46}$ donde se publican artículos sobre mercado y educación.

\section{LA ENSEÑANZA SUPERIOR EN LAS ORGANIZACIONES INTERGUBERNAMENTALES}

La problemática de la educación superior es objeto de estudio en los organismos regionales e intergubernamentales que se están consolidando, cada vez más, en todos los lugares del planeta. Sin duda alguna entre estas organizaciones la que más nos interesa conocer es la Unión Europea y todo el debate que está generando el denominado Espacio Europeo de Educación Superior. Pero antes de entrar en la temática de la Unión Europea, a modo de preámbulo nada más podemos recordar lo que hace la OCDE en el ámbito de la educación superior, y, como epílogo, podemos también introducir en la dinámica que se está generando en Iberoamérica bajo la influencia, en este caso, de lo que se está haciendo en el Espacio Europeo.

\subsection{La Organización para la Cooperación y el Desarrollo Económico (OCDE)}

En el año 2001, el centro para la investigación y la innovación en la enseñanza de la OCDE publica un Análisis de las políticas de la educación ${ }^{47}$ en el que se presentan seis escenarios para la educación del futuro. Las nuevas tecnologías y el mercado se presentan como escenarios preponderantes. Los problemas que se esbozan en este análisis como la dualización social, la enseñanza centrada en contenidos, el aprendizaje a lo largo de la vida... apuntan todos ellos a problemas de fondo que este informe de expertos invita a profundizar.

En el año 2002 se crea en la OCDE una Dirección de Educación y Gestión de Enseñanza Superior ${ }^{48} \mathrm{con}$ el fin de responder mejor a las preocupaciones crecientes

43. http://www.monde-diplomatique.fr/2001/03/WARDE/14880.

44. http://www.oale.org/cadre2/actu/cad2-ecolegrandmarche2.htm.

45. http://users.skynet.be/aped/Analyses/Art2Them.html\#Anchor-Enseignement-35882.

46. http://www.ecoledemocratique.org/.

47. http://wwwl.oecd.org/publications/e-book/9601032e.pdf.

48. http://oecdpublications.gfi-nb.com/cgi-bin/OECDBookShop.storefront/EN/product/962004082P1 y Le programme sur la gestion des établissements d'enseignement supérieur en 
de los países miembros respecto a la política de educación superior. La dirección ha elaborado un programa de trabajo con seis objetivos: ligar la política de formación a lo largo de la vida a los otros ámbitos de acción socioeconómica, evaluar y mejorar los resultados de la educación, favorecer la enseñanza de calidad, repensar la enseñanza superior en una economía mundial, reforzar la cohesión social mediante la formación y construir un futuro nuevo a través de la educación.

El trabajo del Programa sobre la gestión de establecimientos de enseñanza superior (IMHE-Institutional Management in Higher Education) ${ }^{49}$, que fue creado en 1969 y que hoy agrupa a 200 miembros de 34 países diferentes, se integra particularmente en el cuarto de estos objetivos. La edición de 2004 Education at a Glance ${ }^{50}$ dedica una atención particular a la calidad de los resultados de la educación. Por primera vez figuran los indicadores sobre la evolución de la rentabilidad de la educación en el mercado del trabajo. Entre los proyectos piloto que en la actualidad tiene el programa sobre la gestión de los establecimientos de enseñanza superior 2002-2004 se puede consultar http://oecdpublications.gfinb.com/cgibin/OECDBookShop.storefront/EN/product/962004082P1.

\subsection{La enseñanza superior en el ámbito de la Unión Europea}

En Europa se están movilizando todas las instituciones para generar una profunda transformación de los estudios superiores en toda la región. Tanto los organismos oficiales de la Unión Europea (la Comisión o el Parlamento Europeo) como los Ministerios de Educación, la Universidades y las Asociaciones de Universidades están realizando esfuerzos acelerados para ajustar los estudios superiores a los nuevos contextos actuales.

En mayo de 1998 los ministros de Educación de Francia, Italia, Reino Unido y Alemania firman en París la denominada Declaración de la Sorbon ${ }^{51}$ en la que se propone la necesidad de potenciar una armonización europea en la Educación Superior. La Declaración recibe el apoyo de otros 31 países europeos cuyos ministros de Educación, siguiendo el objetivo iniciado en la Sorbona, firman en junio de 1999 en la conocida Declaración de Bolonia ${ }^{52}$ con el fin de establecer un Espacio Europeo de Educación Superior. Con la finalidad de establecer un apoyo constante a la construcción de este espacio, los ministros de Educación de los países firmantes de la Declaración de Bolonia deciden abordar la creación de un sistema de enseñanza superior fácilmente comprensible y comparable, de más corta duración

http://oecdpublications.gfi-nb.com/cgi-bin/OECDBookShop.storefront/EN/product/962004082P1 Informes actuales en http://www.oecd.org/document/29/0,2340,fr_2649_201185_33772701_1_1_1_1,00.html. 49. http://www.oecd.org/topic/0,2686,fr_2649_34525_1_1_1_1_37455,00.html.

50. http://oecdpublications.gfi-nb.com/cgi-bin/OECDBookShop.storefront/EN/product/962004082P1.

51. Sorbona: http://www.aneca.es/modal_eval/docs/declaracion_sorbona.pdf.

52. Bolonia: http://www.aneca.es/modal_eval/docs/declaracion_bolonia.pdf. 
basado en dos ciclos, con un sistema de créditos comparables y compatibles, de calidad garantizada y promovido desde la interacción universitaria mediante la movilidad de profesores, alumnos y gestores.

En torno a la enseñanza superior otro encuentro de relieve es la Convención de Instituciones Europeas de Enseñanza Superior que tuvo lugar en Salamanca ${ }^{53}$, en el año 2001, para preparar la reunión de ministros de Educación de Praga, en la que se reivindica la educación superior como servicio público, atractivo para personas de cualquier región del mundo, flexible y móvil, que sea competitivo pero que no impida la cooperación y no se convierta en un ámbito exclusivamente comercial. La siguiente reunión tiene lugar en Praga, en mayo de 2001 y es donde se confirman, en el Comunicado de Praga ${ }^{54}$, los objetivos establecidos en Bolonia, con un especial interés en promover la competitividad del Espacio Europeo de Educación Superior y su atractivo para el resto de países del mundo. Ya antes, y esto es muy importante, se había establecido, en marzo del año 2000 en Lisboa, lo que viene en denominarse como estrategia de Lisboa ${ }^{55}$ en donde la formación queda constreñida al ámbito de la competitividad productiva. El último avance se da en la reunión de ministros de Berlín, en septiembre de 2003. En el Comunicado de Berlin ${ }^{56}$ se recoge el importante papel que van a jugar en el futuro las redes y organismos de evaluación de la calidad en el Espacio Europeo. Lo que serán las universidades hasta el 2010 se encuentra en la Declaración de Craz ${ }^{57}$ : después de Berlin el papel de las universidades. La próxima Conferencia Internacional de Ministros se celebrará en mayo de 2005 en Bergen (Noruega).

En el ámbito del Parlamento existe un informe y propuesta de resolución, de mayo de 2002, sobre Las universidades y la enseñanza superior en el espacio europeo del Conocimiento ${ }^{58}$, presentado al Parlamento Europeo en la (2001/2174[INI]).

El Consejo Europeo de Barcelona, en marzo de 2002, en su apartado sobre economía competitiva basada en el conocimiento sitúa y apoya toda la labor que se va haciendo en este campo por la Comisión y que será ratificado en el Consejo de Sevilla 59 .

Los documentos producidos a propósito del espacio europeo universitario, además de las Declaraciones y Comunicados anteriormente citados, son abundantes. Algunos de ellos son los siguientes:

53. Salamanca: http://www.aneca.es/modal_eval/docs/mensaje_convencion_salamanca.pdf.

54. Praga: http://www.bologna-berlin2003.de/pdf/Prague_communiquTheta.pdf.

55. Estrategia de Lisboa: http://ue.eu.int/ueDocs/cms_Data/docs/pressData/en/ec/00100r1.en0.htm.

56. Berlin: http://www.ulpgc.es/hege/almacen/download/6930/Espacio_Europeo_esp.pdf.

57. Graz: http://www.ulpgc.es/hege/almacen/download/6929/eees_DeclFINAL_Graz.pdf.

58. Parlamento: http://www.aneca.es/modal_eval/docs/resolucion_parlamento_europeo_universidades.pdf.

59. Las resoluciones del Consejo de Europa se pueden encontrar en http://ue.eu.int/cms3_applications $/$ Applications $/$ newsRoom/loadBook asp?target $=2004 \&$ bid=76\&lang $=2 \& \mathrm{cmsId}=347$.

(c) Ediciones Universidad de Salamanca

Teor. educ. 17,2005 , pp. 255-285 


\subsubsection{Documentos de interés europeo}

En marzo de 2001 se crea la Asociación Europea de Universidades (AEU) ${ }^{60}$. El Plan de acción ${ }^{61}$ de la AEU para el 2004 y 2005 implica una amplia reflexión sobre la transformación en Europa del ámbito universitario. En este marco se ofrecen varios informes sobre las tendencias en educación superior.

- Disponemos de tres informes sobre las tendencias en educación superior. Es interesante el tercero, que lleva por título Tendencias 200. Progreso bacia el Espacio Europeo de Educación Superior. Cuatro años después de Bolonia: Pasos hacia una reforma sostenible de la Educación Superior en Europa ${ }^{62}$, Informe elaborado para la Asociación Europea de Universidades por Sybille Reichert y Christian Tauch (2003).

- Otros análisis anteriores sobre las tendencias en educación superior: Trends in Learning Structures in Higher Education I, elaborado por Guy Haug and Jette Kirstein ${ }^{63}$ y Trends in Learning Structures in Higher Education II, por Guy Haug y Christian Tauch ${ }^{64}$. El primero, Informe sobre las estructuras y las tendencias de la enseñanza superior europed ${ }^{65}$, preparado en 1999 para la Conferencia de Bolonia, estaba dedicado esencialmente a los países de la Unión Europea. El segundo, Tendencias (II), preparado para las Conferencias de Salamanca y Praga de marzo y mayo del 2001, se alarga a los países que firmaron la Declaración de Bolonia.

- Un estudio interesante sobre Másters y Titulaciones Conjuntas en Europa $^{66}$ (Christian Tauch y Andrejs Rauhvargers, 2002), publicado con el apoyo de la Asociación Europea de Universidades y de la Dirección General de Educación y Cultura de la Comisión Europea.

- Richard de Lavigne, consejero para los ECTS, movido por la demanda del profesorado europeo, ha publicado Créditos ECTS y métodos para su asignación $^{67}$ (marzo de 2003).

60. Los Estatutos de la AEU, aprobados el 31 de marzo de 2001 en la Asamblea General Constituyente en Salamanca y enmendados por la Asamblea General el 19 de abril de 2002 en Roskilde se encuentran en http://www.eua.be/eua/jsp/en/upload/EUA_articles_fr.1095951314194.pdf.

61. http://www.eua.be/eua/jsp/en/upload/Action_Plan_2004_2005_FR.1082543352370.pdf.

62. http://www.crue.org/espaeuro/lastdocs/Traduccion_Tendencias03.pdf.

63. http://www.educa.rcanaria.es/dgui/webDGU/Docs/Trends\%20in\%20Learning\%20Structures\%20in\%20Higher\%20Education\%20I.pdf.

64. http://www.educa.rcanaria.es/dgui/webDGU/Docs/Trends\%20in\%20Learning\%20Structures\%20in\%20Higher\%20Education\%20II.pdf.

65. http://www.crue.org/pdf/trends/Trends2F.pdf.

66. http://www.aneca.es/modal_eval/docs/doc_conv_gral2.pdf.

67. http://www.aneca.es/modal_eval/docs/doc_conv_grall.pdf. 
- Sistema Europeo de Transferencia de Créditos (ECTS) Unión Europea y Países de Próxima Adhesión ${ }^{68}$. Está elaborado con datos extraídos de los análisis sobre las tendencias en educación superior, citados anteriormente.

\subsubsection{Documentos de interés para España}

En España se han producido varios análisis e informes sobre el EEES desde varias instituciones: la Conferencia de Rectores de Universidades Españolas (CRUE), el Consejo de Coordinación Universitaria (CCU), la Agencia Nacional de Evaluación de la Calidad y la Acreditación (ANECA). También hay que considerar la normativa que sobre este ámbito se está produciendo desde el Ministerio de Educación y Ciencia (MEC). Entre la documentación a destacar se encuentra:

- El Sistema Universitario Español y el Espacio Europeo de Educación Superior ${ }^{69}$. Este documento tiene como objetivo informar sobre los aspectos más destacados del proceso de Bolonia y de la importancia que tiene para España, como miembro de la Unión Europea, la adaptación de su sistema universitario al Espacio Europeo de Educación Superior.

- Declaración de Bolonia: adaptación del sistema educativo español a sus directrices. Estudio comparado ${ }^{70}$. Es un documento, fruto de la Conferencia de Rectores de las Universidades Españolas del 14 de diciembre de 2000.

- La integración del sistema universitario español en el espacio europeo de enseñanza superior ${ }^{71}$. Es un documento marco elaborado por el Ministerio de Educación, Cultura y Deportes (febrero de 2003).

- Suplemento Europeo al Título ${ }^{72}$ (septiembre de 2002).

- El crédito europeo y el Sistema Educativo español $l^{33}$. Informe técnico realizado por R. Pagani (2002).

- La duración de los estudios de grado $^{74}$, elaborado por el Grupo de EEES de la Conferencia de Rectores de las Universidades Españolas (CRUE) sobre Espacio Europeo de Enseñanza Superior (16 de junio de 2004).

- Real Decreto 56/2005, de 21 de enero, por el que se regulan los estudios universitarios oficiales de postgrado. Este decreto estuvo precedido por un Proyecto de real decreto por el que se regulan los estudios universitarios oficiales de postgrado ${ }^{75}$. Merece la pena comparar el real decreto y su proyecto.

\footnotetext{
68. http://www.aneca.es/modal_eval/docs/doc_conv_aneca2.pdf.

69. http://www.aneca.es/modal_eval/docs/doc_conv_aneca1.pdf.

70. http://www.ulpgc.es/hege/almacen/download/4854/adaptacion_bologna.doc.

71. http://www.ulpgc.es/hege/almacen/download/4861/integracion_Marco10Feb03.doc.

72. http://www.ulpgc.es/hege/almacen/download/4856/suplemento_europeo_titulo.doc

73. http://www.ulpgc.es/hege/almacen/download/4857/credito_europeo.doc.

74. http://www.crue.org/espaeuro/encuentros/grupotrabajo-vigo-docs.htm.

75. http://eees.universia.es/eees_ProyectoRD_POSTGRADO.pdf.
} 
- Real Decreto 55/2005, de 21 de enero, por el que se establece la estructura de las enseñanzas universitarias y se regulan los estudios universitarios oficiales de grado. Igual que el RD de estudios de postgrado, este decreto estuvo precedido por el Proyecto de real decreto por el que se establece la estructura de las enseñanzas universitarias y se regulan los estudios universitarios oficiales de grado ${ }^{76}$. Interesa igualmente comparar el real decreto y su proyecto previo.

\subsubsection{Documentos de interés para las Facultades de Educación o Pedagogía}

- Tuning Educational Structures in Europe 77 (2003). Tuning es el proyecto de mayor impacto creado por las Universidades Europeas para responder al reto de la Declaración de Bolonia y del Comunicado de Praga y en el que ha participado la Universidad de Deusto como universidad coordinadora. Dentro de este proyecto es de gran interés, para las Facultades de Educación o Pedagogía, el trabajo realizado por el Grupo del Área Temática de Ciencias de la Educación: Competencias Específicas.

- Los Informes Finales de la Primera Convocatoria del Programa de Convergencia de la $A N E C A$ que se pueden bajar de la Oficina de Convergencia Europea de la Universidad de Valencia ${ }^{78}$.

- Los proyectos relacionados con las Facultades de Educación son los Proyectos de titulaciones de Maestros y proyecto de Pedagogía y educación social ${ }^{79}$ que se han compartido en dos redes de trabajo: la RED EDUCACIÓN y la RED MAGISTERIO. Tenemos dos Informes Finales sobre Educación cuyos proyectos fueron aprobados en la primera convocatoria de la ANECA:

- Diseño de las titulaciones de grado de pedagogía y educación socia $^{80}$, coordinado por Aurelio Villa de la Universidad Deusto y elaborado por la RED EDUCACIÓN.

- La adecuación de las Titulaciones de Maestro al Espacio Europeo de Educación Superior. INFORME FINAL ${ }^{81}$.

76. http://eees.universia.es/eees_ProyectoRD_Grado.pdf.

77. http://www.relint.deusto.es/TUNINGProject/index.htm.

78. http://www.uv.es/oce/web\%20castellano/informes1conv.htm en Proyectos de titulaciones http://www.aneca.es/modal_eval/conver_docs_titulos.html.

79. http://www.ugr.es/ magister/proyecto_aneca/actas.htm.

80. http://www.uv.es/oce/web\%20castellano/Pedagogia.pdf.

81. http://www.uv.es/oce/web\%20castellano/informe $\% 20$ final $\% 20$ magisterio\%20(PDF)/ Informe \%20final $\% 20$ Magisterio.pdf. 
La denominada RED EDUCACIÓN se forma a partir de la aprobación por parte de la ANECA del diseño de proyecto sobre las titulaciones de Educación Social y Pedagogía. Hasta llegar al informe final, al que ya hemos aludido, se elaboraron otros estudios que también merece la pena citar:

- Análisis comparado de los estudios superiores de educación en Europa (excepto formación del profesorado). Coordinado por Joan M. ${ }^{\underline{a}}$ Senent, de la Universidad de Valencia, se centró en elaborar un documento de trabajo que se consideró el punto de partida para conocer la perspectiva europea y sus principales tendencias.

- Las titulaciones de Pedagogía y Educación Social en las universidades españolas: planes de estudio y salidas profesionales. Coordinado por Marta Ruiz (UNED) ${ }^{82}$. Son interesantes los datos comparativos de planes, perfiles profesionales y los datos estadísticos que aporta.

- Perfiles profesionales y sus competencias en cada una de las dos titulaciones (Pedagogía y Educación Social), coordinado por Aquilina Fueyo (Oviedo).

- Criterios e indicadores de calidad, coordinado por Joan Mateo (Barcelona).

Todo este proceso de reflexión realizado bajo el paraguas de la ANECA ha sido presentado últimamente (febrero de 2005) en los libros blancos ${ }^{83}$ del Título de Grado en Pedagogía y Educación Social (I y II) y del Título de Grado en Magisterio (I y II). En estos libros de fácil lectura se puede encontrar resumido todo el producto de un laborioso proceso.

El discurso oficial de la Unión Europea se debate en un difícil equilibrio entre la tradición social europea y la política neoliberal de mercado. Ya hemos visto cómo el Parlamento Europeo defiende, contra la comercialización de la educación, el concepto de servicio social público pero, al mismo tiempo, se constata como en la Estrategia de Lisboa, el proyecto educativo está enfocado a la competitividad y a la productividad por encima de todo. En realidad, la Unión Europea, en la Conferencia de Lisboa, se inclina a favor de un modelo de educación productivo que sirva para hacer de Europa la región más competitiva del planeta. Esta opción por un proyecto educativo neoliberal produce tensiones y movimientos complementarios que no deberían ser desconocidos en cualquier investigación sobre la educación superior en Europa.

82. http://www.ucm.es/info/the/eees/lastitul.pdf.

83. http://www.aneca.es/modal_eval/conver_docs_titulos.html. 


\subsubsection{Voces críticas al espacio europeo}

Existen documentos y estudios críticos a la dinámica del espacio europeo que merece la pena tener en cuenta si queremos tener una visión completa de las reflexiones que se hacen en torno a la enseñanza superior.

En Europa, y a título de ejemplo, podemos citar la disonancia interna que se está produciendo en el Partido Socialista Francés (PSF), de la que no se han hecho eco el resto de partidos socialistas europeos. El PSF ha divulgado la reflexión sobre la existencia de dos modelos de sociedad entre los que se debate Europa ${ }^{84}$. A su juicio, la disyuntiva está entre una Europa vieja que opta por la integración del modelo social europeo en el de la mundialización liberal, o el de una Europa de progreso y de justicia que integra la mundialización liberal en su modelo social. Otro ejemplo de reflexión crítica sobre la evolución de la educación en Europa se puede encontrar en diversas asociaciones y organizaciones internacionales ligadas a movimientos de tipo internacional como, por ejemplo, el Foro Social Europeo de octubre del 2004 que abordó temas como el de Otra educación es posible: oposición y resistencia al neoliberalismo.

En España existen movimientos críticos al pensamiento dominante de la UE sobre el EEES. Habría que introducir en este apartado el XI Congreso de Formación del Profesorado ${ }^{85}$ que tuvo lugar en Segovia (17-19 febrero) en el que se cuestionó el paradigma de competencias como modelo dominante para la Enseñanza Superior en Europa. Entre los universitarios, uno de los autores más conocidos en este sentido es Carlos Taibo, quien hace un análisis crítico a la Unión Europea realmente existente (Taibo, 2004). Reflexiones críticas a añadir, en este caso directamente al EEE, las podemos encontrar en los profesores Teresa Gómez del Castillo y Antonio Aguilera, de la Universidad de Sevilla, citados anteriormente. Una de sus publicaciones, Perspectivas de la universidad española en el Espacio Europeo de Educación Superior ${ }^{86}$, la podemos encontrar en Internet.

\subsection{La enseñanza superior en Iberoamérica}

En la región iberoamericana también existe una gran preocupación por la transformación del sistema de enseñanza superior. En los últimos años del siglo XX las grandes tendencias que rigieron a la universidad fueron la masificación y la diversificación institucional, luego la evaluación, la internacionalización y la mercantilización. Ahora, se apunta hacia la convergencia de los sistemas de educación superior. La convergencia de los sistemas universitarios de América Latina y su

84. Oui a l'Europe federale et sociale, non a la constitution Giscard en http://www.parti-socialiste. fr/list_theme.php?theme=MTY0.

85. http://www.aufop.org/xi-congreso/listacomunicacionesSG.asp.

86. http://www.ull.es/publicaciones/latina/20041257aguilera.htm. 
articulación con el espacio común europeo se dibujan como un contraproceso frente a la "caótica heterogeneidad institucional" que, según el investigador Norberto Fernández Lamarra, implicó la explosión de la educación superior ocurrida tras 1950 .

\subsubsection{La Organización de Estados Iberoamericanos}

La Organización de Estados Iberoamericanos (OEI) ha abordado el tema de la enseñanza superior en varias de las 14 Cumbres de Ministros de Educación, desde la que se celebró en La Habana en 1988 hasta la última que acaba de celebrarse en San José de Costa Rica en octubre de 2004 . El documento de consulta ${ }^{87}$, presentado en la Conferencia de 1995, sobre la educación como factor de desarrollo, aborda los temas claves del entorno educativo: su rentabilidad económica, su rentabilidad social y humana. Sugiere intermitentemente la necesidad de trascender el modelo economicista, tanto del desarrollo como de la educación, para centrarse en un nuevo modelo de desarrollo sostenible y de educación integral o en lo que algunos especialistas denominan como "trilogía del bienestar", que promueva la estabilidad política, el crecimiento sostenible y las políticas sociales, orientadas a la igualdad de oportunidades. Señala que no habría que olvidar que la educación, además de su valor económico, constituye un derecho social, por lo que no se deben olvidar las dificultades y los logros que ha supuesto su universalización y consagración como tal derecho.

El Área de Educación Superior de la Organización de Estados Iberoamericanos $^{88}$ va encauzando las políticas de las universidades iberoamericanas y, en concreto, todo un proceso de convergencia similar al iniciado en Europa. La Red Iberoamericana para la Acreditación de la Calidad de la Educación Superior (RIACES) y el Programa de Intercambio de Movilidad Académica (PIMA), entre estudiantes y profesores universitarios iberoamericanos, siguen los pasos de proyectos similares europeos. La Revista Iberoamericana de Educación, en su n. 021 , del año 1999, aborda el tema monográfico sobre la Universidad en el siglo XXI ${ }^{89}$.

La OEI mantiene en sus declaraciones una retórica constante de equilibrio y tensión entre lo que podríamos denominar el discurso neoliberal del Consenso de Washington y el discurso social de la Cumbre Social de Copenhague de 1995. A pesar de esta retórica política, la realidad social se deteriora progresivamente, siendo América Latina la región más desigual del planeta, cuyos índices de pobreza dificultan el acceso a la generación y a los beneficios del crecimiento económico a cerca de 200 millones de personas, así lo declaran los ministros de Educación en la última conferencia de octubre de 2004 en San José de Costa Rica.

87. Este documento fue elaborado por Raúl Urzúa, Manuel de Puelles y José Ignacio Torreblanca.

88. http://www.oei.es/superior.htm.

89. http://www.campus-oei.org/revista/rie21f.htm. 


\subsubsection{El Instituto Internacional de la UNESCO para la Educación Superior en América Latina y el Caribe}

El Instituto Internacional de la UNESCO para la Educación Superior en América Latina y el Caribe (IESALC) ${ }^{90}$ es un órgano autónomo, adscrito a la UNESCO, que da continuidad a las actividades que durante veinte años desarrolló el CRESALC, en el ámbito de la educación superior, en la región latinoamericana. Su sede se encuentra en la ciudad de Caracas. Realiza análisis y estudios sobre la enseñanza superior tanto regionales (América Latina y el Caribe, América Central, el Caribe) como por países (Estudio sobre República Dominicana, Honduras, Paraguay, Perú, Puerto Rico, etc.). Los temas que estudia suelen ser: la legislación, las editoriales universitarias, la formación docente, los postgrados, la educación virtual, las reformas universitarias, etc. Cualquier persona inquieta por el conocimiento de los cambios y la situación de la enseñanza universitaria en Iberoamérica no puede marginar los análisis del IESALC.

\subsubsection{El Consejo Universitario Iberoamericano}

El Consejo Universitario Iberoamericano (CUIB) ${ }^{91}$ que se constituyó en Cartagena de Indias (Colombia), el 21 de noviembre de 2002, es una organización no gubernamental que se configura como una red de redes de las universidades iberoamericanas. Está integrado por las organizaciones nacionales representativas de las universidades y otras instituciones de educación superior de los países que integran la comunidad iberoamericana de naciones ${ }^{92}$. Persigue, entre otros, los siguientes objetivos: promover la creación y consolidación de un Espacio Iberoamericano de la Educación Superior y la Investigación e impulsar la cooperación entre las universidades.

\subsubsection{La Organización Universitaria Interamericana}

La Organización Universitaria Interamericana93 (OUI), fundada en 1979 en Quebec (Canadá), es la única asociación de instituciones y organizaciones de educación superior en las Américas (América Central, Brasil, Canadá, Caribe, Cono Sur, Estados Unidos, México y Países Andinos) y es un portavoz privilegiado ante la Organización de Estados Americanos, el Banco Interamericano de Desarrollo y el Banco Mundial.

90. http://www.iesalc.unesco.org.ve/.

91. http://www.cuib.org/index.htm.

92. Estos países son: Argentina, Bolivia, Brasil, Chile, Colombia, Costa Rica, Cuba, Ecuador, El Salvador, España, Guatemala, Honduras, México, Nicaragua, Panamá, Paraguay, Perú, Portugal, República Dominicana, Uruguay y Venezuela.

93. http://www.oui-iohe.qc.ca/INDX/es-index.htm. 


\subsubsection{MERCOSUR}

Dentro del área del sector educativo de MERCOSUR (que incluye a Argentina, junto a Brasil, Paraguay y Uruguay, más Bolivia y Chile como asociados) los respectivos gobiernos -más representantes de universidades públicas y privadas y del sector productivo- han desarrollado el Mecanismo Experimental de Acreditación de Carreras (MEXA) 94

\subsubsection{Cooperación Europa, América Latina y el Caribe: Espacio Común de Enseñanza Superior}

La Primera Cumbre de Jefes de Estado y de Gobierno de los países de la Unión Europea, América Latina, el Caribe (UEALC), con la participación del presidente de la Comisión Europea, se celebró en junio de 1999 en la ciudad de Río de Janeiro.

-En la Conferencia de París ${ }^{95}$ del año 2000, los ministros de Educación manifestaron que era necesario un marco de acción para una cooperación profunda que favoreciera la emergencia de un Espacio Común de Enseñanza Superior UEALC, como un elemento clave para el fortalecimiento de las relaciones bilaterales y multilaterales entre los Estados y que tuviera por vocación el facilitar la circulación de experiencias, el traspaso de tecnologías y el intercambio de estudiantes, profesores, investigadores y personal administrativo, velando por la articulación entre formación, empleo y conocimiento científico. Para ello se tomó como punto de apoyo la cooperación bilateral y multilateral existente y se apeló a las instituciones oficiales encargadas de la enseñanza superior y al resto de organizaciones que podían apoyar la Declaración para favorecer su puesta en marcha.

Este espacio común es coherente con los principios y objetivos adoptados por los ministros de Investigación y Tecnología de América Latina, el Caribe y la Unión Europea en su reunión de Brasilia los días 21 y 22 de marzo de 2002 . Merece la pena la lectura detenida ${ }^{96}$ de la Segunda Reunión Plenaria del CUIB, celebrada en Porto Alegre (Brasil) en noviembre del 2003, en donde se debatió la calidad y los sistemas de evaluación y acreditación de la educación superior en Iberoamérica, la educación superior, la inclusión social y la construcción de un espacio común de educación superior entre la Unión Europea y los países de América Latina y el Caribe. Últimamente el CUIB ha firmado varios convenios significativos con la OEI y con la EUA:

94. http://www.unap.cl/p4_unap/site/artic/20040920/pags/20040920103310.html.

95. http://www.aneca.es/present/docs/declaracion_paris.pdf.

96. http://www.cuib.org/cuib.pdf. 
- Convenio marco de colaboración entre el Consejo Universitario Iberomericano (CUIB) y la Organización de Estados Iberoamericanos (OEI) $)^{97}$ en Madrid, a 24 de septiembre de 2004.

- Convenio marco de colaboración entre el Consejo Universitario Iberoamericano (CUIB) y la European University Association (EUA) ${ }^{98}$.

\section{INFORMES OFICIALES DE DIFERENTES PAÍSES SOBRE ENSEÑANZA SUPERIOR}

Diferentes gobiernos de muchos países han mantenido una gran inquietud sobre sus propios sistemas de enseñanza superior y esto ha ocurrido así tanto en los países industrializados como en los países en desarrollo. Los ejemplos más recientes de ello provienen de Nueva Zelanda (Libro verde sobre educación terciaria, 1998, e Informe del Grupo de trabajo especial, 2001); Suráfrica (Informe del Consejo de Educación Superior, 2000); Australia (Agenda para la economía del conocimiento, 2001) e India (India como superpotencia del conocimiento: estrategia de transformación, 2001). El Informe Boyer (EE.UU.) o el Informe ANUIES (México) han tenido repercusión en el ámbito americano. No habría que olvidar el reciente Informe Brunner (Santiago de Chile 2005) sobre la educación superior en Chile ${ }^{99}$, en el contexto internacional de los estudios superiores así como la Obra de Jocelyne Gacel-Ávila sobre la internacionalización de la educación superior ${ }^{100}$. En el ámbito europeo, los que más incidencia han tenido han sido los realizados en el Reino Unido (Informe Dearing, 1997), en Francia (Informe Attali, 1998), el de España (Informe Bricall, 2000). Vamos a detenernos en estos tres últimos.

\subsection{Informe Dearing ${ }^{101}$ (Reino Unido)}

Cuando los rectores españoles pidieron el denominado informe Bricall, tenían en mente el encargo de 1996 del Gobierno conservador británico a Ron Dearing. Este documento fue entregado al Ejecutivo laborista de Tony Blair en 1997, quien asumió sus propuestas. La financiación universitaria era el principal reto del informe.

El informe Higher education in the learning society fue redactado por un hombre de negocios británico, Ron Dearing, a instancias del Gobierno conservador de John Major en 1996. Dearing no es un académico, sino un empresario que también se había encargado de la reconversión del servicio de Correos. Este perfil

97. http://www.crue.org/pdf/ConveniomarcocolaboracionCUIB_OEI.pdf.

98. http://www.crue.org/pdf/Convenio\%20CUIB-EUA\%20(Espa\%F1ol).pdf.

99. http://www.uai.cl/p4_home/site/asocfile/ASOCFILE120050121095042.pdf.

100. GaCel-Ávila, J. (2003) La internacionalización de la educación superior. México, Universidad de Guadalajara.

101. http://www.ucm.es/info/DAP/pr2/3_ibyd/3_07_dc/3_07_3.htm. 
financiero explica su elección para reformar la universidad, siempre con problemas económicos. Su principal novedad era que los estudiantes pagaran una mayor parte del coste de su enseñanza, aunque fuera después de licenciarse. También explica las líneas maestras de su propuesta: el Estado debe aumentar el gasto público en enseñanza universitaria, al menos al mismo ritmo que aumente el producto interior bruto de un país, y los alumnos que tienen recursos económicos deben hacer una contribución mayor a sus propios costes. Para todos los demás, dice, la educación superior abre la posibilidad dé mejorar la calidad de vida y es justo pagar por ello.

Otra cuestión en la que el informe Dearing insiste es en la formación continua de los universitarios. No sólo por las evidentes ventajas para los estudiantes, que pueden promocionar más fácilmente en sus empleos, sino porque esta educación debe ser una fuente de financiación creciente para los centros docentes, al impartirse a profesionales que ya están trabajando y que, probablemente, cuenten con el apoyo económico de las empresas que van a beneficiarse de los nuevos conocimientos adquiridos.

Lo que este estudio aborda es la previsión de que a lo largo de las dos próximas décadas, el Reino Unido, en todos sus niveles de compromiso -Estado, individuos, empresas, instituciones educativas, etc.-, debe crear un estilo de sociedad acorde con la idea de la formación continua y el aprendizaje de postgrado. Se espera que en estas próximas décadas la enseñanza superior se reforzará gracias a los planes de calidad y podrá así contribuir al desarrollo de una sociedad de aprendizaje e investigación. En consecuencia la enseñanza superior se verá sometida a una gran demanda debido al incremento del número de estudiantes de todas las edades y con todos los tipos de dedicación (tiempo completo o parcial).

\subsection{Informe Attali (1998 Francia)}

Jacques Attali ha realizado la última propuesta de reforma de la Universidad francesa a través de su informe Pour un modèle européen d'enseignement supérieur $^{102}$ solicitado por el ministro francés de Educación, Claude Allègre. Por primera vez, desde mayo del 68 , una propuesta de reforma universitaria no era cuestionada por los alumnos. Como ex presidente del Banco Europeo de Reconstrucción y Desarrollo sugiere un cambio radical en los sistemas de financiación de las universidades y recomienda la creación de una Agencia Superior de Evaluación, un servicio estatal responsable de evaluar los centros educativos. Lo que pretendía Attali era algo revolucionario: distribuir los fondos públicos destinados a la universidad, no en función de criterios exclusivamente cuantitativos (número de estudiantes, de profesores o los metros cuadrados del campus), sino en función de

102. http://www.education.gouv.fr/forum/attali1.htm. 
criterios más cualitativos, como el número de doctores, las publicaciones de los profesores en revistas de prestigio científico, las veces que éstas citaban a un centro o a su personal docente y la integración posterior de sus alumnos en la vida profesional.

Para Jacques Attali las universidades se encuentran en una situación frágil y enfrentadas a cuatro revoluciones que son la de las ciencias y las tecnologías, la de los lazos con el Estado, la de las relaciones con las empresas y la del modo de aprender los saberes. Las misiones que se analizan son las de permitir a cada estudiante adquirir el nivel máximo de excelencia, hacer progresar el conocimiento, adaptarse a las nuevas profesiones, hacer progresar la justicia social y acelerar la apertura al mundo.

\subsection{El Informe Bricall (España)}

Este informe que lleva por título Universidad $2000^{103}$ parte del déficit de reflexión que subsiste en torno a muchos de los problemas universitarios actuales y hace referencia a las modificaciones sustanciales que están teniendo lugar en el ámbito de la educación superior; modificaciones que afectan no sólo a la naturaleza de dicho nivel de enseñanza, sino a la inserción de las instituciones que lo prestan en el conjunto de la sociedad. Los temas que aborda son: la universidad como agente social, la difusión del conocimiento, formar para aprender, generación y aplicación del conocimiento, la financiación, el personal de la universidad, la calidad y acreditación, el gobierno y las redes tecnológicas y universitarias.

\subsection{Otros informes y documentos españoles sobre la universidad}

Existen otros muchos documentos y análisis españoles sobre la enseñanza superior, no relacionados directamente con el EEES.

El Consejo de Coordinación Universitaria ${ }^{104}$ ha publicado varios análisis sociológicos sobre las características del alumnado universitario que nos pueden ser muy útiles para, combinados con otros análisis europeos, conocer más en profundidad nuestra realidad universitaria en el contexto europeo y mundial. Veamos algunos de ellos que no precisan mucho comentario en el contexto de esta publicación. Son, en este caso, estudios de tipo sociológico que necesitarían, de ponerse, una interpretación amplia.

- Informe sobre la evolución del alumnado universitario de 1994-95 a 2001-02 $2^{105}$ (diciembre de 2003).

103. http://www.crue.org/informeuniv2000.htm.

104. www.mec.es/consejou.

105. http://wwwn.mec.es/educa/ccuniv/html/informes_y_estudios/documentos/informe_ sobre_alumnado.pdf. 
- $\quad$ Métodos de análisis de la inserción laboral de los universitarios (2003) ${ }^{106}$.

- Estudio sobre la oferta, demanda y matrícula de nuevo ingreso en las universidades públicas para el curso 2003-2004. (Revisado el 29 de abril de $2004)^{107}$.

La Agencia Nacional de Evaluación de la Calidad y la Acreditación (ANECA) también ha publicado estudios e informes de interés entre los que recogemos:

- Los universitarios españoles y el mercado laboral ${ }^{108}$. Avance de resultados, 2004.

- Los españoles y la Universidad. Primera encuesta nacional sobre la imagen pública del sistema universitario español ${ }^{109}$, publicado en junio de 2004.

- Evolución de la matrícula en la titulación de Pedagogía y de educación Social en sección 1.1.3 y 1.2.3. del estudio de RED EDUCACIÓN, al que ya hemos aludido y que lleva por título Las titulaciones de Pedagogía y Educación Social en las universidades españolas: planes de estudio y salidas profesionales. Coordinado por Marta Ruiz (UNED) ${ }^{110}$.

El Ministerio de Educación y Ciencia ofrece información sobre la normativa y sobre datos sociológicos importantes como son:

- Estadísticas universitarias en Datos $20032004^{111}$.

- Encuesta de Inserción Laboral: Relación entre educación superior y empleo. Problemas de la última década elaborado por la Agencia Nacional de Evaluación de la Calidad y Acreditación.

- La Universidad española en cifras (año 2004) ${ }^{112}$.

- Legislación Universitaria ${ }^{113}$.

Además de los organismos ya citados, merece la pena tener en cuenta la información que prestan otros organismos españoles sobre la educación superior. Algunos ejemplos pueden ser los siguientes: ral.pdf.

106. http://wwwn.mec.es/educa/ccuniv/html/informes_y_estudios/documentos/Insercion_labo-

107. http://wwwn.mec.es/educa/jsp/plantilla.jsp?area=ccuniv\&id=251 y http://wwwn.mec.es/ educa/ccuniv/html/informes_y_estudios/documentos/Oferta_Demanda_2003_04.pdf.

108 http://www.aneca.es/comunic/docs/boletines/boletin15/insercionlaboral_estudiantes_ envio.pdf.

109. http://www.aneca.es/publicaciones/docs/Imagenpublica_ampliada.pdf.

110. http://www.ucm.es/info/the/eees/lastitul.pdf.

111. http://wwwn.mec.es/educa/jsp/plantilla.jsp?area=ccuniv\&id=E128.

112. http://www.ujaen.es/serv/gerencia/webestudiocrue04/index.htm.

113. http://wwwn.mec.es/univ/jsp/plantilla.jsp?id=1711. 
- La Conferencia de Rectores de las Universidades Españolas (CRUE) ${ }^{114}$ es un espacio de información de gran interés. Junto con la Cátedra UNESCO de Gestión de la Educación Superior de la Universitat Politècnica de Catalunya (UPC), la CRUE mantiene el Observatorio Universitario ${ }^{115}$ y ofrecen, además, un Boletín de Educación Superior, publicación electrónica que se distribuye mensualmente a través de Internet.

- El Observatorio del Instituto Valenciano de Investigaciones Económicas (IVIE) $)^{116}$, con el patrocinio de Bancaja, publica un Observatorio de inserción laboral de los jóvenes.

- Las Cátedras de la UNESCO de Educación Superior ${ }^{117}$ disponen información relevante sobre universidades y educación superior de todo el mundo.

- La Oficina de la Convergencia Europea en Valencia ${ }^{118}$ ofrece algunos documentos del EEES.

\section{A MODO DE CONCLUSIÓN}

Como puede constatarse, los documentos son abundantes. No hemos pretendido que estén reseñados todos los que son, pero sí que sean todos los que están. Creemos que con este material se puede iniciar una investigación sobre uno de los temas que más puede afectar a la sociedad del futuro, como lo es el de la educación superior. A nuestro juicio los teóricos de la educación han de verse emplazados a reflexionar sobre distintos aspectos que el nuevo Espacio Europeo de Educación Superior viene arrastrando y que los documentos reseñados provocan intermitentemente. Señalamos solamente tres, entre otros posibles:

En primer lugar, creemos que el gran objetivo de este artículo estaría cumplido si los teóricos de la educación no convierten la información aquí contenida en teoría sino que utilizan la información para pensar y para construir, con ella, conocimiento y, si es posible, sabiduría.

En segundo lugar, pensamos que el contenido de toda esta información ha de provocar un esfuerzo teórico por diseñar paradigmas de enseñanza superior que tengan en cuenta las necesidades no sólo de la población europea sino de toda la población del planeta. La construcción y expansión del conocimiento no ha de provocar beneficios solamente en una de las regiones del mundo más poderosas sino en todas las regiones. En este sentido, el triángulo calidad, equidad y libertad de la

114. http://www.crue.org/.

115. http://www.crue.org/observatorio.htm.

116. http://obrasocial.bancaja.es/accesible/capital/observatorio.htm.

117. http://portal.unesco.org/education/es/ev.phpURL_ID=6954\&URL_DO=DO_TOPIC\& URL_SECTION=201.html.

118. http://www.uv.es/oce/web\%20castellano/informes1conv.htm. 
enseñanza superior merece una atención detenida por parte de los teóricos de la educación.

Finalmente, se necesita una atención más intensa de los teóricos de la educación para verificar si el paradigma de las competencias que imanta todo el modelo de educación superior en Europa es el que ha de dominar el futuro del quehacer universitario o existen otros paradigmas que, además de aprender a hacer y a trabajar, permitan aprender a pensar, a imaginar, a sentir y a consentir entre los distintos pueblos que están avocados no solamente supervivir sino también a vivir y a convivir.

\section{BIBLIOGRAFÍA}

Por comodidad para el lector, hemos ido poniendo, en nota a pie de página, las direcciones donde pueden encontrarse los distintos documentos, todas ellas revisadas a 28 de enero de 2005 . Aconsejamos que, en el caso de que pulsando en la dirección indicada, no se obtenga el resultado buscado, se introduzca en algún buscador el nombre completo del documento en cuestión y aseguramos que, en un alto porcentaje, se obtendrán los documentos.

AUGÉ, M. (1992) Los no lugares. ¿Espacios del anonimato? Barcelona, Editorial Gedisa.

Brunner, J. J.; Elaceua, G.; Tillett, A.; Bonnefoy, J.; González, S.; Pacheco, P. y Salazar, F. (2005) Guiar el mercado. Informe sobre la educación superior en Chile. Santiago de Chile, Universidad Adolfo Ibáñez.

ClaRK, R. B. (1998) Creating Entrepreneurial Universities. Organizacional Patbways of Transformation. Oxford, Pergamon-IAU Press.

CORAGgio, J. L y TORRES, R. M. (1997) La educación según el Banco Mundial. Un análisis de sus propuestas y métodos. Buenos Aires, Editorial Miño y Dávila.

De SELYS, G. (1998) L'école, grand marché du XXI ${ }^{\mathrm{e}}$ siècle, Le Monde diplomatique, juin, 14-15.

Gómez del CAstillo, M. T. y Aguilera Jiménez, A. (2004) Perspectivas de la universidad española en el espacio europeo de educación superior, Revista Latina de Comunicación Social, 57.

HIRT, N. (2002) Los tres ejes de la mercantilización escolar. Madrid, Edita CAUM.

MedialdeA, B. y ALonso, V. (2004) Las reformas neoliberales de la educación en el mundo. Madrid, Edita Club amigos de la UNESCO de Madrid.

MORIN, E. (2001) El método: la bumanidad de la bumanidad. La identidad bumana. Madrid, Cátedra.

TAIBO, C. (2004) No es lo que nos cuentan. Una crítica a la Unión Europea realmente existente. Barcelona, Ediciones B, S.A. 